\title{
Research on the Sustainable Development Path of Government Communication against the Background of New Media
}

\author{
Jian Chen* \\ International Business Faculty, \\ Beijing Normal University, Zhuhai \\ Zhuhai, P.R.China
}

\author{
Qiang Yuan \\ International Business Faculty, \\ Beijing Normal University, Zhuhai \\ Zhuhai, P.R.China
}

\author{
Yunhai Lai \\ International Business Faculty, \\ Beijing Normal University, Zhuhai \\ Zhuhai, P.R.China
}

\begin{abstract}
To face the public emergencies, local governments must conduct "new media" public communication to ensure that information can be communicated to the masses timely, to pledge that the information is seasonably paying attention to the truthfulness, comprehensiveness and accuracy of information, so that the masses can trust the government after receiving the information and act in an orderly manner. This paper summarizes the Zhuhai Government's public communication path in the new media environment, combining with the foreign government's public communication management experience and the changes in the public communication environment brought by the new media environment, taking the typhoon "Hato" incident as an example to conduct a comprehensive investigation and questionnaire analysis, and analyzing the typhoon "Hato" incident satisfaction, meanwhile summing up the public communication path with Zhuhai characteristics as well as putting forward the suggestions for improvement.
\end{abstract}

Keywords-new media; government communication; public relations; public communication management

\section{INTRODUCTION}

New media refers to the carrier of information dissemination by means of computers (or digital devices with the essential characteristics of computers). "Digitalization" and "interactivity" are the fundamental characteristics of new media.

Under the new media environment, there is still much space for improvement in the concept, measures and content presentation of communication between the government and the public. The traditional media, such as newspapers, radio, television and other means of communication that regularly publish information to the public, can no longer meet the current needs of public communication. How to meet the basic demands of the government and the masses in the new media era, and to explore the communication path between the government and the public as well as improve strategy of the communication path has become an important issue.

\section{TYPHOON HATO}

\section{A. Background}

At 12:00 on August 23, 2017, No. 13 Typhoon Hato landed in the southern coastal area of Zhuhai. It was the strongest typhoon landing in China in the whole year. It was also one of the strongest typhoons landing in Guangdong since 1949. At the time of landing, the Central Meteorological Station issued its first typhoon red warning last year. The typhoon lasted for one day and caused great damage to the city of Zhuhai.

\section{B. Process Analysis}

According to the "news section" of Zhuhai Municipal Government's official website broadcasting typhoon "Tianpigeon" incident, many municipal government departments and municipal institutions participated in the disaster relief work. First, the city's three defense headquarters received the typhoon warning and held a defense conference. Municipal government departments launched emergency plans, and districts and counties responded positively to the typhoon arrival. From 23th to 24th, the Municipal Science, Industry and Telecommunications Radio Management Office will be on duty 24 hours to ensure the smooth flow of information. After the typhoon passed, the municipal government immediately convened a meeting of the Municipal Standing Committee to deploy the work of disaster relief and recovery. The Municipal Safety Supervision Bureau, Municipal Industry and Commerce Bureau, Municipal Health and Family Planning Bureau, Municipal Food and Drug Control Bureau, Municipal Environmental Health Bureau, Civil Affairs Bureau, Municipal Transportation Bureau and Municipal Municipal Municipal Forestry Bureau removed hidden dangers, assessed losses caused by disasters and main Pavement cleaning, rescue and resettlement of the affected people, pavement repair and pavement cleaning and facility maintenance from several different perspectives for emergency relief and disaster relief. Following Typhoon Pakhar on 27, a meeting of the Municipal Standing Committee was held again, the content of the meeting 
was as the following: focusing on post-disaster reconstruction, post-disaster epidemic prevention as well as high temperature release, visits to affected communities and enterprises and ensuring that the school season starts in September as usual. In mid-September, the incident was summarized and rethought by the Municipal Standing Committee.

\section{SURVEY OF ZHUHAI CITIZENS' ATtITUDES}

Through questionnaires, we know the degree of Zhuhai citizens' concern about current events and their attitudes towards public communication and information dissemination of Zhuhai municipal government, in addition, the results of cross-tabulation and chi-square test.

\section{A. Data Acquisition}

The questionnaire was published online through Tencent Questionnaire from March 16 to 20, 2018. It is available to the public in the form of website links. A total of 361 valid questionnaires were collected, with an effective rate of $75.1 \%$. In order to ensure the authenticity of the survey subjects, the questionnaire limits the survey subjects to Zhuhai citizens who have lived in Zhuhai for more than one year.

\section{B. Questionnaire Analysis}

Statistical survey results show that more than $70 \%$ of respondents will take the initiative to pay attention to Zhuhai current affairs news, $31 \%$ pay attention relatively more to the others, $23 \%$ will not take the initiative to pay attention, and $4 \%$ will not pay attention at all. Only $10.2 \%$ of the respondents were interested in current affairs news, and only $21.9 \%$ of the Typhoon Hato incidents knew the progress of the incidents through the official website of the government.

There are $72.3 \%$ of the respondents said they were uncertain, unclear and totally unaware of where to find information released by relevant agencies of Zhuhai Municipal Government. Furthermore, there are $61.3 \%$ of the respondents had searched for relevant information released by Zhuhai Municipal Government because they wanted to know the current events in Zhuhai. Combined with the data of "attention to current affairs in Zhuhai", it can be inferred that most of the citizens were more concerned about current affairs in Zhuhai. About half of the information about the relevant behavior of the municipal government is obtained from third-party media, but not through the official website of the municipal government.

The questionnaire shows more than $70 \%$ of the respondents said they were satisfied with the action of the Zhuhai Municipal Government in the Typhoon Hato incident and believed that the information was released in time. Comparing the daily use of APP in Zhuhai and the progress of Typhoon Hato incident, we found that the three most important news apps were Tencent News, Today's Headlines and Sina Weibo. More than $80 \%$ of the respondents said that they need to organize the timeline of the progress of emergencies so as to facilitate the public to understand the progress of emergencies and maintain information symmetry.

According to the above cross-tabulation analysis of gender, age and type of work, the proportion of male respondents who expressed dissatisfaction and not completely satisfied is significantly higher than that of females, The proportion of respondents under 18 and over 50 who expressed dissatisfaction and not completely satisfied was significantly higher than that of other age groups. The author divided the work types into six categories (Schedule B). Among them, the proportion of "communication" and "production" respondents who expressed dissatisfaction and not completely satisfied was significantly higher than that of other types of work.

In summary, the main groups of respondents who did not report the "Typhoon Hato" incident timely by the government were male, adolescent, elderly, communication and production workers.

\section{Current Problems In Public COMMUnicAtion}

Combining with the analysis of the process of the "Typhoon Hato" incident and the results of the questionnaire survey on Zhuhai citizens' attitudes, this paper puts forward the existing problems in public communication of Zhuhai government.

\section{A. Not timely Handled}

At present, the news content about the "Typhoon Hato" incident on the official website of Zhuhai Municipal Government is mostly transferred from the "ZHUHAI DAILY". There are few special reports on the progress of the incident, and most of them are reports on the work of various government departments. Most of the upload time and content occurrence time have a " equation of time" of at least two days, and no relevant reports has been found about the incident in which the government opens channels of communication for public inquiry. Relevant reports are mostly on-site communication or post-visit communication.

\section{B. Not Fully Utilized New Media Channels}

After searching, it was found that Zhuhai Municipal Government has set up new media communication channels such as website, WeChat Public account, etc. However, there are some phenomena that they are only opened channels but not maintained, have contents but they had low quality, or only have channels but they are without contents.

\section{Not Strong Enough Communication Awareness}

In addition to not finding relevant reports of "Typhoon Hato" on the opening of public inquiry and communication channels on the official website of Zhuhai Municipal Government, the "complaint" under its "consultation interaction" column only shows the latest six items. To view all the contents, you need to click on "I want to consult" or "I want to complain", enter the second-level web page, and then click on "consultation feedback" to see all the feedback and consultation history. And when searching for news related to the "Typhoon Hato" incident, if only through the "typhoon, Tiange" keyword to search, the results showed are chaotic, there is no time- sequence and no summary report of the event.

\section{SUGGESTIONS}

Combining the second part of foreign experience and the third part of Zhuhai public events, the following three suggestions are given. 


\section{A. Public Communication Ways Suggested}

After analysis, it's believes that Zhuhai government should strengthen public communication in two aspects. Firstly, actively release information. The government should ensure the details of the event are sorted out and published on the government information disclosure website within two days after the occurrence of public events, and update the progress of the event orderly. Secondly, communicate with the public timely about the events. The government is supposed to make good use of existing WeChat subscription resources such as Zhuhai Issued and Zhuhai Emergency to provide communicable paths for the public by using the functions of comment and background message. It can also upload the established live broadcast website in the report of corresponding events to communicate with the public.

\section{B. Specify Communication Process}

When public events occur, the government should take timely measures to deal with them. Besides, it should pay attention to synchronized communication, to ensure that information can be accurately conveyed to the public, to eliminate rumors and to deal with public opinion positively.

\section{Accurate Information Publish}

Facing public emergencies, local governments should not only take prompt action, but also actively publish relevant information about the events, clarify the causes of the events and current progress. Local governments should publish how to work on the emergencies, satisfy the wishes of the masses, stabilize the situation, respect the citizens' right to know about relevant information, help to establish a correct understanding, grasp the dominant power of public opinion, and guide the positive public opinion.

\section{Correctly Disseminate Information and Media}

As for the self-Media groups rising with the new media environment, the government should not underestimate their influence. The government also needs to improve the supervision and censorship system, ensure the authenticity of information dissemination, and allow the voice of doubt to exist. However, in order to prevent others from misleading the public with ulterior motives, it is prohibited to make incitement speech freely.

\section{E. Correctly Treat Public Feedback}

Using new media to broaden information channels, establish and provide communication channels, such as setting up the feedback function of government WeChat public service number, opening the network telephone hotline, so that the first reaction of the masses is to give feedback and inquiry to the relevant organizations, rather than acquiescing that the government is not communicable, and disseminating and publishing criticism of the government directly on the network.

\section{F. Updated Social Understanding}

The public can easily interact on the Internet, but the ultra-fast transmission and the unknown authenticity of information become the hidden danger of social media communication, and the process of information dissemination is vulnerable to noise interference. Once an emergency occurs, there will be relevant information reports on the Internet. The government should not only handle the emergency in action, but also communicate in time. It is necessary to let the masses know the measures and attitudes of the government.

\section{G. Integration of Government Information}

Improve information collection and establish a unified information base, which can integrate and share information data scattered in different government departments on the same platform, so that the government can reach agreement on events, synchronize awareness, facilitate information viewing and access. It is convenient for different departments and units to cooperate in emergencies by constructing their own large data system within the government, and for experts and government-specific emergency committees to refer to.

\section{H. Guarantee Information Disclosure Quality}

It's need to guarantee the timeliness and accuracy of information and open channels for regular maintenance. It is suggested that in emergencies, details and progress of events should be publicized regularly every day, and information publishing and integration system should be established. After relevant information or data publishing, it should be arranged in chronological order, marked with traceable data sources, and summarized in the designated government website section for reference. The Department of WeChat Public Number has been built to ensure the quality of information publicity in terms of content and form, taking into accounts the practicability and dissemination of push content.

\section{CONCLUSION}

In summary, the government should not only perform its duties in behavior, but also publish timely and voluntary information to let the public know the contents of the government's work, and understand public opinion, so as to help achieve a better development atmosphere.

\section{REFERENCES}

[1] Yan Wenbo. On the life cycle theory model of new media paradox [J]. Journal of Hangzhou Normal University (Social Science Edition), 2014, 36(02) pp. 112-117.

[2] Fraser P. Sitel Public Relations Practice [M] Beijing:Tsinghua University Press, 2014.41.

[3] Damion Waymer. Democracy and government public relations: Expanding the scope of Relationship in public relations research. Public Relations Review, 2013, pp. 320-331.

[4] LIN Aizhen, SUN Wei. Government Crisis Management and Public Opinion Guidance in New Media Environment[J]. China Emergency Management, 2011(03): 20-25.

[5] Li LU Wei. In the face of network public events, how does the government handle the "rudder" of public opinion [J]. People's Forum, 2017 (11) pp. 64-65.

[6] Zhong Weijun, Huang Yimeng. The Transformation of Social Media and Crisis Communication Theory: From SCCT to SMCC [J]. Journal of University of Electronic Science and Technology of China (Social Science Edition), 2016, 18(05): 12-16+25.

[7] Zhang Xiaona. CNNIC released the 40th "Statistical Report on the Development of China's Internet Network" [N]. Democratic and Legal Times, 2017-08-08 (001) 